\title{
Custo da produção de silagens em sistemas de integração lavoura-pecuária sob plantio direto ${ }^{1}$
}

\author{
Nídia Raquel Costa*2, Marcelo Andreotti ${ }^{3}$, Antônio Fernando Bergamaschine ${ }^{4}$, \\ Keny Samejima Mascarenhas Lopes ${ }^{5}$, Ana Eliza da Silva Lima ${ }^{6}$ \\ http://dx.doi.org/10.1590/0034-737X201562010002
}

\section{RESUMO}

Objetivou-se, com este trabalho, avaliar o custo operacional total (COT) da produção de silagens em sistemas produtivos de Integração Lavoura-Pecuária (ILP), a produtividade de massa seca (PMS) e a quantidade de proteína bruta (PB) e nutrientes digestíveis totais (NDT), por área, em cada modalidade de cultivo sob condições irrigadas, no Cerrado, durante dois anos agrícolas (2010/2011 e 2011/2012). O delineamento experimental foi o de blocos casualizados, com quatro repetições, sendo os tratamentos constituídos de três modalidades de cultivo das culturas do milho e do sorgo para silagem (solteiro; em consórcio com a Brachiaria brizantha cv. Xaraés e com Panicum maximum cv. Tanzânia). Constatou-se que a silagem de sorgo apresentou custo de produção inferior ao da silagem de milho. Os maiores COTs foram obtidos no consórcio de milho com capim Xaraés ( $\mathrm{R} \$ 2.046,93$ e de R \$2.385,40) e, os menores, nos cultivos de sorgo solteiro ( $\mathrm{R} \$ 1.815,93$ e de $\mathrm{R} \$ 1.941,62)$, para os dois anos agrícolas. Os tratamentos com cultivos exclusivos (de sorgo e de milho) proporcionaram maiores valores de PMS no primeiro ano; porém, no segundo ano, os maiores valores foram proporcionados pelos cultivos consorciados de ambas as espécies com Panicum maximum cv. Tanzânia. Os valores de PB e NDT por área variaram entre os tratamentos nos dois anos agrícolas e seguiram o padrão da PMS, sendo os maiores valores proporcionados também pelos consórcios de sorgo e milho com o capim Tanzânia.

Palavras-Chave: Zea mays, Sorghum bicolor, Brachiaria brizantha, Panicum maximum, custo operacional total.

\section{ABSTRACT}

\section{Cost of the silage production crop-livestock integrated under no-tillage system}

The objective of this work was to evaluate the total operational cost (TOC) in silage production in the croplivestock integrated system (CLIS), the dry matter yield (DMY), as well as the amount of crude protein (CP) and total digestible nutrients (TDN) per area in each crop modality under irrigated conditions in the Brazilian Cerrado during two growing seasons (2010/2011 and 2011/2012). The experimental design was a randomized block, with four replications, with the treatments constituted of three modalities of cultivation of corn and sorghum crops for silage (single, intercropped with Brachiaria brizantha cv. Xaraés and Panicum maximum cv. Tanzânia). It was found in this study that the sorghum silage presented lower production cost than corn silage. The highest TOC was obtained by corn intercropped with Xaraés (BR \$ 2,046.93 and BR \$2,385.40), and the lowest in a single sorghum crop (BR\$ 1,815.93 and BR \$ 1,941.62) for both years. Treatments with single crop (sorghum and corn) provided

\footnotetext{
Submetido em 22/11/2012 e aprovado em 05/12/2014

${ }^{t}$ Parte da tese de doutorado da primeira autora.

${ }^{2}$ Universidade Estadual Paulista, Faculdade de Engenharia de Ilha Solteira, Ilha Solteira, São Paulo, Brasil. nidiarcosta@gmail.com

${ }^{3}$ Universidade Estadual Paulista, Faculdade de Engenharia de Ilha Solteira, Ilha Solteira, São Paulo, Brasil. dreotti@agr.feis.unesp.br

${ }^{4}$ Universidade Estadual Paulista, Faculdade de Engenharia de Ilha solteira, Ilha Solteira, São Paulo, Brasil. berga @ bio.feis.unesp.br

${ }^{5}$ Universidade Estadual Paulista, Faculdade de Engenharia de Ilha solteira, Ilha Solteira, São Paulo, Brasil. keny.unesp.zoo@hotmail.com

${ }^{6}$ Universidade Estadual Paulista, Faculdade de Engenharia de Ilha Solteira, Ilha Solteira, São Paulo, Brasil. anael_lima@ig.com.br

*Autor para correspondência: nidiarcosta@gmail.com
} 
higher values of DMY in the first season; however, in the second season, the highest values of DMY were provided by the intercropped system of both species with Panicum maximum cv. Tanzânia. The values of CP and TDN per area varied among the treatments in the two growing seasons and followed the DMY pattern, where the highest values were also provided by sorghum or corn intercropped with Tanzânia grass.

Key Word: Brachiaria brizantha, Panicum maximum, Sorghum bicolor total operational cost, Zea mays.

\section{INTRODUÇÃO}

Os sistemas de Integração Lavoura-Pecuária (ILP) são definidos, de acordo com Macedo (2009), como o conjunto de sistemas produtivos que buscam maior sustentabilidade na propriedade rural e que envolvem, em uma mesma área, a produção de grãos, consorciados, ou não, com espécies forrageiras e com a produção animal. Desta maneira, a semeadura das culturas pode ser realizada de forma simultânea, sequencial ou rotacionada, o que garante maior eficiência na utilização da área agrícola durante todo o ano, melhor aproveitamento do maquinário disponível e do efeito residual de corretivos e de fertilizantes, melhorando, assim, as condições sociais no meio rural com diminuição dos impactos ambientais.

A escassez de alimentos volumosos durante o período de inverno, principalmente na região de Cerrado, faz, muitas vezes, que os produtores procurem armazenar alimentos de melhor valor nutricional, na forma de silagem, para a nutrição dos animais nesse período. $\mathrm{O}$ milho, tradicionalmente, é a cultura mais utilizada para produção de silagem, pois, além de apresentar composição bromatológica que preenche as exigências para confecção de uma boa silagem, proporciona boa fermentação microbiana (Nussio et al., 2001). De acordo com Pereira et al. (2004), a cultura é uma das mais utilizadas no processo de ensilagem para ruminantes, por seu elevado valor energético, baixo teor de fibra, alta produção de matéria seca por unidade de área, facilidade de colheita mecânica e bons padrões de fermentação da silagem, sem a necessidade de utilização de aditivos ou pré-secagem.

Entretanto, segundo Molina et al. (2003), a cultura do sorgo vem crescendo e representa grande percentual da área cultivada para produção de silagem, no Brasil. Grande parte desse crescimento advém da alta produtividade, do bom valor nutritivo e, principalmente, da tolerância a déficits hídricos ocasionais. Apesar de a silagem de sorgo ser considerada de valor nutritivo inferior à de milho, sua ensilagem vem-se destacando, pois essa cultura apresenta rebrotas após os cortes, obtendo-se até $60 \%$ da produção do primeiro corte, e não concorre com a alimentação humana, sendo, portanto, de custo mais reduzido. Além disso, alguns cultivares ou híbridos de sorgo apresentam maior produção de matéria seca e de matéria verde por unidade de área que o milho (Zago, 2002).

No tocante às culturas, há resultados de pesquisa que comprovam a eficiência do sistema de integração Lavoura-Pecuária (ILP) sob sistema plantio direto (SPD), quando desenvolvido seguindo seus fundamentos básicos, ao proporcionar produção igual ou superior a dos sistemas constituídos somente com o cultivo exclusivo (Nicoloso et al., 2006). Portanto, torna-se de fundamental importância, em sistemas complexos como a ILP, o conhecimento dos custos de produção, para auxiliar na tomada de decisão, quanto a formas de manejo que, além de promoverem aumento da produtividade, resultem em redução de custos e minimizem riscos ambientais. Em função dos resultados obtidos, o consórcio de culturas anuais com forrageiras é uma promissora opção econômica de produção de grãos (Trecenti et al., 2008; Pariz et al., 2009; Garcia et al., 2012) e de forragem na entressafra (Pariz et al., 2011; Costa et al., 2012), além de proporcionar resultados sócioeconômicos e ambientais positivos (Kluthcouski et al., 2000; Landers, 2007; Tracy \& Zhang, 2008; Crusciol et al., 2012).

Assim, objetivou-se, com este trabalho, avaliar, em um Latossolo Vermelho distroférrico, sob condições irrigadas, no Cerrado, o custo operacional total (COT) da produção de silagens em sistemas produtivos na integração Lavoura-Pecuária (ILP), assim como a produtividade de massa seca, proteína bruta e nutrientes digestíveis totais por área, durante dois anos agrícolas (2010/2011 e 2011/2012).

\section{MATERIAL E MÉTODOS}

O experimento foi instalado no ano agrícola de 2010/ 2011, na Fazenda de Ensino, Pesquisa e Extensão, pertencente à Faculdade de Engenharia, Campus de Ilha Sol- 
teira (FE/Unesp), área de Produção Vegetal, localizada no município de Selvíria, Estado de Mato Grosso do Sul $\left(20^{\circ} 20^{\prime} 05^{\prime \prime S}\right.$ e $51^{\circ} 24^{\prime} 26^{\prime \prime} \mathrm{W}$, altitude de $\left.335 \mathrm{~m}\right)$. A área experimental encontrava-se sob sistema de plantio direto (SPD) há oito anos, com culturas anuais e perenes para formação de palhada, sendo a cultura anterior à instalação do experimento o milho (safra 2009/2010).

O tipo climático é Aw, segundo classificação de Köppen, caracterizado como tropical úmido, com estação chuvosa, no verão e, seca, no inverno. Na Figura 1, estão apresentados os dados de precipitação pluvial, as temperaturas mínimas, médias e máximas, além do fotoperíodo durante a realização do experimento.

A área foi irrigada por aspersão (pivô central), considerando-se o intervalo hídrico ótimo para as culturas em estudo. Para estabelecer a capacidade de água disponível (CAD) utilizou-se a equação:

$\mathrm{CAD}(\mathrm{mm})=[(\mathrm{CC}-\mathrm{PMM}) / 100] \times \mathrm{DS} \times \mathrm{PESR} ;$

em que CC é a capacidade de campo (\%), PMM é o ponto de murcha permanente (\%), DS é a densidade do solo $\left(\mathrm{g} \mathrm{dm}^{-3}\right)$ e PESR é a profundidade efetiva do sistema radicular $(\mathrm{m})$. Esses dados foram obtidos a partir da curva de retenção de água do solo, sendo $\mathrm{CC}=20,25 \%$, $\mathrm{PMM}=14,58 \%, \mathrm{DS}=1.310$ e $1.340 \mathrm{~g} \mathrm{dm}^{-3}$ (safras 2010/ 2011 e 2011/2012, respectivamente) e PESR $=0,20 \mathrm{~m}$. Portanto, a CAD avaliada do solo foi de 14,86 e 15,20 mm (safras 2010/2011 e 2011/2012, respectivamente).

O suprimento de água foi transmitido com um fluxo de $3,3 \mathrm{~mm} \mathrm{~h}^{-1}$. A irrigação foi aplicada cada vez que a evapotranspiração máxima da cultura (ETm) atingia 8,25 $\mathrm{mm}$ (menos de 44,3\% da CAD). A ETm foi estimada por meio da equação:

$\operatorname{ETm}\left(m m \operatorname{dia}^{-1}\right)=\mathrm{Kc} \times \mathrm{ETo} ;$ em que Kc é o coeficiente da cultura e ETo é a evapotranspiração de referência.

A ETo foi estimada por meio da equação:

$$
\text { ETo }\left(m m \operatorname{dia}^{-1}\right)=\mathrm{Kp} \times \mathrm{ECA}
$$

em que Kp é o coeficiente do tanque Classe A e ECA é a evaporação do tanque Classe $\mathrm{A}\left(\mathrm{mm} \mathrm{dia}^{-1}\right)$. A mensuração da evaporação da água $(\mathrm{mm})$ foi obtida diariamente a partir de um tanque Classe A. O Kp foi calculado como proposto por Doorenbos \& Pruitt (1977) com base na área circundante, velocidade do vento e umidade relativa do ar.

O solo da área é um Latossolo Vermelho distroférrico típico muito argiloso, classificado conforme Embrapa (2006). Os atributos físicos e químicos, anteriormente à instalação do experimento (safra 2010/2011), na camada de 0 a $0,20 \mathrm{~m}$ do solo apresentaram os seguintes valores: densidade do solo $=1,310 \mathrm{~kg} \mathrm{dm}^{-3}$; macro, micro e porosidade total $=0,147 ; 0,334$ e $0,481 \mathrm{~m}^{3} \mathrm{~m}^{-3}$, respectivamente; $\mathrm{pH}\left(\mathrm{CaCl}_{2}\right)=5,1 ; \mathrm{M} . \mathrm{O} .=25 \mathrm{~g} \mathrm{dm}^{-3} ; \mathrm{H}+\mathrm{Al}=$

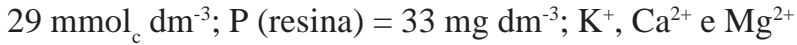
$=4,1 ; 28,0$ e $16,0 \mathrm{mmol}_{\mathrm{c}} \mathrm{dm}^{-3}$, respectivamente, e $\mathrm{V}=$ $62 \%$. Na safra 2011/2012, os atributos referentes à fertilidade do solo, também na camada de 0 a $0,20 \mathrm{~m}$ de profundidade, apresentaram os seguintes valores: $\mathrm{pH}$ $\left(\mathrm{CaCl}_{2}\right)=5,4 ;$ M.O. $=22,4 \mathrm{~g} \mathrm{dm}^{-3} ; \mathrm{H}+\mathrm{Al}=40,3 \mathrm{mmol}_{c}$ $\mathrm{dm}^{-3} ; \mathrm{P}($ resina $)=20,4 \mathrm{mg} \mathrm{dm}{ }^{-3} ; \mathrm{K}^{+}, \mathrm{Ca}^{2+} \mathrm{e} \mathrm{Mg}^{2+}=3,4$; 17,0 e $9,9 \mathrm{mmol}_{\mathrm{c}} \mathrm{dm}^{-3}$, respectivamente, e $\mathrm{V}=43 \%$.

Antes da instalação do experimento, foi efetuada dessecação da área, visando à formação de palhada para início da integração Lavoura-Pecuária (ILP) sob sistema plantio direto (SPD), utilizando-se o herbicida Glyphosate (1,44 kg ha-1 do ingrediente ativo (i.a.)), com posterior manejo com triturador horizontal de resíduos

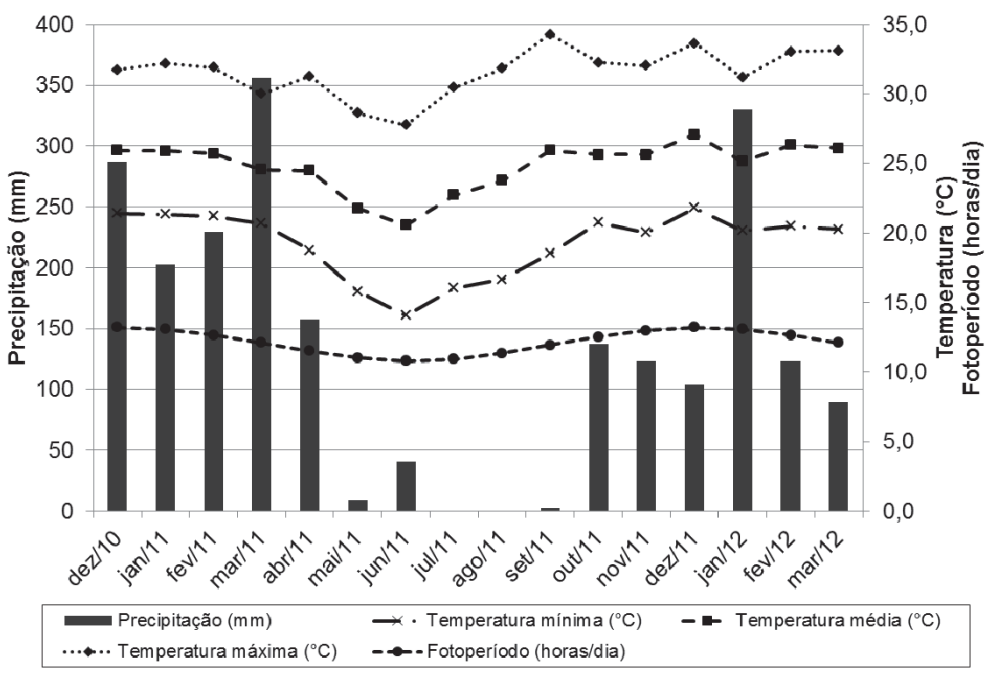

Figura 1. Dados climáticos obtidos junto à estação meteorológica situada na Fazenda de Ensino, Pesquisa e Extensão da FE/UNESP, no município de Selvíria, Mato Grosso do Sul. Período de Dezembro/2010 a Março/2012. 
vegetais (triton), sendo esse manejo adotado nos dois anos de avaliação.

O delineamento experimental foi o de blocos casualizados, com quatro repetições, sendo os tratamentos constituídos de três modalidades de cultivo do milho e do sorgo para silagem (exclusivamente, ou seja, solteiro; em consórcio com a Brachiaria brizantha cv. Xaraés e com Panicum maximum cv. Tanzânia). As forrageiras foram semeadas simultaneamente nas entrelinhas das culturas de grãos. A área experimental totalizava $2.176 \mathrm{~m}^{2}$ e cada parcela continha $68 \mathrm{~m}^{2}$.

A implantação do experimento ocorreu em 02/12/ 2010, quando a cultura do milho (híbrido triplo BG 7049) foi semeada com semeadora-adubadora com mecanismo sulcador do tipo haste (facão), para SPD, a uma profundidade de aproximadamente $0,05 \mathrm{~m}$, espaçamento de $0,90 \mathrm{~m}$ e cerca de 5,4 sementes $\mathrm{m}^{-1}$, objetivando-se atingir um estande final próximo de 55.000 a 60.000 plantas $\mathrm{ha}^{-1}$. Para a semeadura do sorgo forrageiro cv.Volumax (Sorghum bicolor (L.) Moench), foram seguidos os mesmos procedimentos descritos anteriormente para a semeadura do milho, sendo as sementes de sorgo semeadas em espaçamento de $0,34 \mathrm{~m}$, com aproximadamente 15 a 20 sementes $\mathrm{m}^{-1}$.

A semeadura das forrageiras foi realizada simultaneamente com a do milho e a do sorgo, sendo efetuada com outra semeadora-adubadora, com mecanismo sulcador do tipo disco duplo desencontrado, para SPD, realizando-se a semeadura nas entrelinhas das culturas de grãos. As sementes foram depositadas na profundidade de 0,08 m, no espaçamento de 0,34 m, utilizando-se aproximadamente 532 pontos de valor cultural (VC) por hectare $\left(7 \mathrm{~kg} \mathrm{ha}^{-1}\right.$ de sementes puras viáveis com VC de 76 a $72 \%$ ) para a Brachiaria brizantha cv. Xaraés e para o Panicum maximum cv. Tanzânia, respectivamente. As sementes das espécies forrageiras localizaram-se, dessa forma, abaixo das sementes de milho e sorgo, seguindo as recomendações de Kluthcouski et al. (2000), com o objetivo de atrasar a emergência dos capins em relação a das culturas de grãos e diminuir a provável competição entre as espécies, no período inicial de desenvolvimento das culturas.

Foi realizada adubação de semeadura, nas culturas de grãos, em ambos os anos agrícolas, com aplicação de $250 \mathrm{~kg} \mathrm{ha}^{-1}$ do formulado 08-28-16 (20 kg ha-1 de N, 70 $\mathrm{kg} \mathrm{ha}^{-1}$ de $\mathrm{P}_{2} \mathrm{O}_{5}$ e $40 \mathrm{~kg} \mathrm{ha}^{-1}$ de $\mathrm{K}_{2} \mathrm{O}$, respectivamente). Como tratamento de sementes do milho, foi feita a aplicação de $150 \mathrm{~g} \mathrm{~L}^{-1}$ i. a. imidacloprido $+450 \mathrm{~g} \mathrm{~L}^{-1}$ i.a. tiodicarbe. Para o controle de insetos em ambas as culturas, em 30/12/2010 e 06/01/2011, aplicaram-se 129 $\mathrm{g} \mathrm{ha}^{-1}$ i.a metomil $+24 \mathrm{~g} \mathrm{ha}^{-1}$ i.a. triflumurom, por meio de pulverizador tratorizado de barras, com $12 \mathrm{~m}$ de comprimento, com bicos tipo leque, espaçados em 0,50 m.
Como adubação de cobertura, foi feita a aplicação de 90 $\mathrm{kg} \mathrm{ha}^{-1}$ de $\mathrm{N}$ (fonte ureia) em 05/01/2011 e em 12/12/ 2011, quando o milho atingiu o estádio fenológico V4 (quatro folhas totalmente desenvolvidas) e quando o sorgo apresentou-se com cerca de quatro a seis folhas totalmente desenvolvidas, irrigando-se a área, em seguida, a fim de evitar perdas excessivas de $\mathrm{N}$ por volatilização. A adubação de cobertura foi realizada próxima às linhas das culturas de grãos.

A altura de colheita para silagem foi de aproximadamente $0,30 \mathrm{~m}$ da superfície do solo, sendo realizada para a cultura do milho no dia 19/03/2011, quando esta apresentava em torno de 30 a 35\% de matéria seca (MS) (farináceo ou farináceo - duro). Para o sorgo, o corte foi feito no dia 25/03/2011, quando este se encontrava com aproximadamente $70 \%$ de MS nos grãos (maturidade fisiológica). De acordo com Ferreira (2001) o ponto ideal para ensilagem é quando a planta forrageira atinge de 28 a $35 \%$ de MS, fase que, em espécies como o milho e o sorgo, coincide com a máxima qualidade nutricional.

Por ocasião da colheita com colhedora de forragem (modelo JF 90), o material foi picado em partículas médias de $2,5 \mathrm{~cm}$, armazenado e adequadamente compactado em baldes plásticos com capacidade para $15 \mathrm{~kg}$ de matéria verde, com flanges de silicone adaptados às tampas (válvula de Bunsen), para permitir o escoamento de gases, e areia, no fundo, para a recuperação do efluente. Após o enchimento, os baldes foram hermeticamente lacrados, com fitas adesivas, para evitar a troca de ar com o meio, sendo que os silos foram abertos com 60 dias após vedação, em 27/05/2011 e 12/05/ 2012, para os dois anos agrícolas avaliados, respectivamente. Estes procedimentos foram efetuados por causa das condições experimentais na realização do trabalho de pesquisa. Para o cálculo do custo da produção das silagens, foram consideradas as condições reais de campo, simulando-se as operações e instalações adequadas para este tipo de sistema produtivo, tendo-se o cuidado de realizar pesquisas com produtores da região.

Foram determinadas a produtividade de massa seca, das diferentes silagens produzidas, por área $\left(\mathrm{kg} \mathrm{ha}^{-1}\right)$. Para tanto, coletaram-se, em $1 \mathrm{~m}^{2}$, as espécies cultivadas exclusivamente, ou seja, solteiras, e em consórcio com a $B$. brizantha e $P$. maximum, em três pontos distintos dentro de cada unidade experimental, com uso de um quadrado de metal (1,0 m x 1,0 m), adotando-se, como referência, o corte a aproximadamente $0,30 \mathrm{~m}$ da superfície do solo. Após este procedimento, as amostras foram secadas em estufa, a $65^{\circ} \mathrm{C}$, até massa constante, calculando-se posteriormente a produtividade de massa seca (PMS) das silagens $\left(\mathrm{kg} \mathrm{ha}^{-1}\right)$.

Decorridos cerca de 60 dias após a ensilagem do material, foram coletadas quatro amostras de cada trata- 
mento, para determinação dos componentes bromatológicos. Essas amostras foram secadas em estufa, a $65^{\circ}$, até massa constante, para posterior análise laboratorial. Desta maneira, avaliaram-se os teores de proteína bruta (PB), de acordo com metodologia descrita em Silva \& Queiroz (2002) e os de nutrientes digestíveis totais (NDT), de acordo com metodologia contida no NRC (2001): NDT $=\left[\mathrm{PBD}+(2,25 \times\right.$ AGD $)+\mathrm{FDN}_{\mathrm{cp}} \mathrm{D}+$ CNFD]- 7; em que: $\mathrm{PBD}=\mathrm{PBxEXP}^{[-1,2 \mathrm{x}(\mathrm{PIDA} / \mathrm{PB})]} ; \mathrm{AGD}$ $=\mathrm{EE}=$ matéria solúvel no tratamento com éter de petróleo, se EE <1; AG = 0; FDN ${ }_{\mathrm{cp}} \mathrm{D}=[0,75 \mathrm{x}(\mathrm{FDNcp}-$ LIG)] x [1- $\left.\left(\mathrm{LIG} / \mathrm{FDN}_{\mathrm{cp}}\right)^{0,667}\right]$ em que: FDNcp $=$ FDN corrigido para cinzas e proteína; $\mathrm{CNFD}=0,98 \times\{100-$ $[($ FDN - PIDN $)+$ PB + EE + CINZAS $]\} \times$ PAF, adotando-se PAF (fator de ajuste ao processamento) $=1$. Posteriormente, os resultados foram expressos por área, extrapolando-se os valores obtidos em $\mathrm{kg} \mathrm{ha}^{-1}$. Assim, a quantidade de PB e NDT produzida por área $\left(\mathrm{kg} \mathrm{ha}^{-1}\right)$ foi obtida pelo produto da produção de matéria seca (PMS) por área $\left(\mathrm{kg} \mathrm{ha}^{-1}\right)$ e o teor de PB e NDT na MS das silagens, em percentagem.

Para a condução do experimento no segundo ano agrícola avaliado (2011/2012), foram adotados os mesmos procedimentos descritos anteriormente para instalação e condução do experimento na safra 2010/2011, exceto o híbrido de milho utilizado. Na primeira safra utilizouse o híbrido triplo BG 7049 e, na segunda, (2011/2012), o híbrido simples AG 8088 YG. Na condução do experimento no segundo ano agrícola, as semeaduras em cultivo exclusivo (solteiro) ou em consórcio ocorreram em 10/11/2011 e as colheitas para ensilagem nos dias 24/ 02/2012, para os tratamentos com a cultura do milho, e em 12/03/2012 para os tratamentos com a cultura do sorgo, em virtude da diferença de maturação das duas espécies.

Os atributos referentes às culturas em estudo tiveram os resultados médios submetidos à análise de variância, pelo teste $\mathrm{F}(\mathrm{p}<0,05)$, e foram comparados pelo teste de Tukey a $5 \%$ de probabilidade. Todos os cálculos foram efetuados com o programa estatístico Sisvar $^{\circledR}$ (Ferreira, 1999).

A metodologia de cálculo de custo utilizada foi a do custo operacional total (COT) de produção, de acordo com Matsunaga et al. (1976) e Montes et al. (2006), que é constituído da soma das despesas diretas de custeio: operações realizadas, insumos (adubos, sementes, defensivos, etc.), mão de obra, maquinário e irrigação, denominada de custo operacional efetivo (COE). Para as despesas indiretas, como depreciações, encargos sociais e financeiros, foram considerados $5 \%$ do COE (Matsunaga et al., 1976), resultando, portanto, no custo operacional total (COT), que foram extrapolados para um hectare (Tabela 1).
Os dados apresentados neste trabalho foram obtidos em condições experimentais, porém, para facilitar a determinação dos coeficientes econômicos, os valores foram extrapolados para condições reais de campo, de acordo com as práticas normalmente realizadas por produtores da região.

Os custos das operações mecanizadas foram obtidos do Agrianual (2011, 2012) e Anualpec (2010), ajustados aos valores médios de aluguel praticados na região, nos quais já estão incluídos a mão de obra do tratorista, os gastos com combustíveis e lubrificantes, bem como a depreciação de máquinas e equipamentos. Os coeficientes técnicos e os valores unitários utilizados foram obtidos junto aos técnicos e produtores regionais que trabalham com essas culturas e apresentam nível tecnológico semelhante. Para as outras despesas, foram considerados os preços médios pagos na região em estudo, ajustados àqueles vigentes em lavouras comerciais em São Paulo para os anos agrícolas 2010/2011 e 2011/ 2012.

Visto que a pesquisa foi realizada em uma Fazenda de Ensino, Pesquisa e Extensão, não se consideraram os itens relacionados aos custos fixos da atividade, como remuneração da terra, pro-labore do produtor, além de juros de instalações, benfeitorias, máquinas e equipamentos.

A nomenclatura utilizada neste trabalho considera as espécies, utilizadas em consórcio ou exclusivamente, sendo: MS: milho semeado exclusivamente (solteiro); MB: milho em consórcio com a Brachiaria brizantha cv. Xaraés; MP: milho em consórcio com o Panicum maximum cv. Tanzânia; SS: sorgo semeado exclusivamente (solteiro); SB: sorgo em consórcio com a Brachiaria brizantha cv. Xaraés e SP: sorgo em consórcio com o Panicum maximum cv. Tanzânia, respectivamente.

\section{RESULTADOS E DISCUSSÃO}

Os investimentos iniciais com preparo de solo e calagem não foram considerados nesta pesquisa, uma vez que essas práticas não foram realizadas, principalmente por se tratar de uma área com oito anos de adoção do sistema plantio direto (SPD) no momento da instalação dos experimentos. Esse fato contribuiu para reduzir os custos iniciais com a implantação dos consórcios para produção de silagem. Os custos operacionais totais e efetivos, registrados no experimento, para a obtenção do desempenho econômico dos sistemas de produção avaliados, foram extrapolados para um hectare (Tabela 1). Esse modelo de estrutura de custo operacional total (COT) foi utilizado em todos os sistemas de produção, nos dois anos agrícolas avaliados. 
Verifica-se que as operações que mais oneraram os custos de produção das silagens foram a colheita do material para ensilagem, seguida do transporte da forragem e da irrigação da área, totalizando mais de 57\% dos custos operacionais efetivos, nos dois anos agrícolas avaliados (Tabela 1).

De maneira geral, observa-se, na Tabela 1, que os custos com os insumos, principalmente os fertilizantes e sementes, foram os componentes que mais oneraram os sistemas produtivos analisados. No caso das espécies forrageiras, o elevado preço das sementes deveu-se ao seu alto VC, de 76 a $72 \%$ para a $B$. brizantha e $P$. maximum respectivamente, apresentando uma participação média nos gastos de aproximadamente $43,6 \%$ do COE, no primeiro ano (2010/2011), e de 50,4\%, no segundo (2011/2012). O aumento dos custos de produção no segundo ano de avaliação advém, principalmente, da elevação dos custos das sementes, insumos e defensi- vos agrícolas, em comparação com os do primeiro ano, e também pelo fato de a semente de milho híbrido (AG 8088 YG), utilizada no ano agrícola 2011/2012, apresentar preço mais elevado, chegando ao dobro do valor pago pelo híbrido utilizado na primeira safra. Assim, essa oscilação de preços ao longo dos anos pode influenciar nos resultados econômicos dos sistemas produtivos.

$\mathrm{O}$ alto custo da adubação ocorreu em função da elevada exigência do consórcio das culturas produtoras de grãos com as forrageiras, demandando grande quantidade desses insumos para altas produtividades de silagem, caracterizado ainda pela alta extração e exportação de nutrientes (Tabela 2).

Um fator importante a ser considerado foi a não aplicação de herbicidas normalmente utilizados durante o desenvolvimento das culturas em questão, uma vez que a ausência desta operação gera economia. De acordo Entz et al. (2002), em trabalho realizado no norte das grandes

Tabela 1. Estimativa do custo operacional total da produção de silagem para o tratamento MB (milho em consórcio com a B. brizantha cv. Xaraés), em um hectare sob sistema plantio direto, em Selvíria, Mato Grosso do Sul. Safra 2010/2011

\begin{tabular}{|c|c|c|c|c|}
\hline \multirow{2}{*}{ Descrição } & \multirow{2}{*}{ Unidade $^{(1)}$} & \multirow{2}{*}{ Quantidade } & Valor Unitário & Valor Total \\
\hline & & & \multicolumn{2}{|c|}{$\mathbf{R} \$$} \\
\hline \multicolumn{5}{|l|}{ A- Operações } \\
\hline Dessecação & HM & 0,5 & 50,00 & 25,00 \\
\hline Roçagem (Triton) & HM & 1,0 & 45,00 & 45,00 \\
\hline Semeadura do milho & HM & 0,7 & 130,00 & 91,00 \\
\hline Semeadura braquiária & HM & 0,7 & 130,00 & 91,00 \\
\hline Adubação de cobertura do milho & $\mathrm{HM}$ & 0,6 & 50,00 & 30,00 \\
\hline Colheita do milho/braquiaria silagem & $\mathrm{HM}$ & 3,00 & 105,00 & 315,00 \\
\hline Transporte da silagem & HM & 1,50 & 70,00 & 105,00 \\
\hline Compactação da silagem & $\mathrm{HM}$ & 1,50 & 55,00 & 82,50 \\
\hline Pulverização $(2 \mathrm{x})$ & HM & 1,00 & 50,00 & 50,00 \\
\hline Irrigação (pivô) & $\mathrm{mm}$ & 100,00 & 1,33 & 133,00 \\
\hline Subtotal A & & & & 967,50 \\
\hline \multicolumn{5}{|l|}{ B- Insumos } \\
\hline \multicolumn{5}{|l|}{ B1- Fertilizantes } \\
\hline Adubo N-P-K (08-28-16) & $\mathrm{kg} \mathrm{ha}^{-1}$ & 250 & 1,10 & 275,00 \\
\hline Ureia (cobertura) & $\mathrm{kg} \mathrm{ha}^{-1}$ & 200 & 1,40 & 280,00 \\
\hline \multicolumn{5}{|l|}{ B2- Sementes } \\
\hline Milho (BG 7049) & sc ha ${ }^{-1}$ & 1 & 200,00 & 200,00 \\
\hline Brachiaria brizantha cv. Xarés & $\mathrm{kg} \mathrm{ha}^{-1}$ & 7 & 13,50 & 94,50 \\
\hline \multicolumn{5}{|l|}{ B3- Defensivos Agrícolas } \\
\hline Herbicida Glyphosate & $1 \mathrm{ha}^{-1}$ & 4,00 & 12,00 & 48,00 \\
\hline Inseticida imidacloprido + tiodicarbe & $1 \mathrm{ha}^{-1}$ & 0,30 & 115,00 & 34,50 \\
\hline Inseticida metomil $(2 \mathrm{x})$ & $1 \mathrm{ha}^{-1}$ & 1,20 & 16,80 & 20,16 \\
\hline Inseticida triflumurom $(2 \mathrm{x})$ & $1 \mathrm{ha}^{-1}$ & 0,20 & 149,00 & 29,80 \\
\hline Subtotal B & & & & 981,96 \\
\hline Custo Operacional Efetivo (COE) $(\mathrm{A}+\mathrm{B})$ & & & & 1949,46 \\
\hline C- Outras Despesas ${ }^{(2)}$ & & & & 97,47 \\
\hline Subtotal C & & & & 97,47 \\
\hline Custo Operacional Total $(\mathrm{COT})(\mathrm{A}+\mathrm{B}+\mathrm{C})$ & & & & 2046,93 \\
\hline \multicolumn{5}{|c|}{ (1) $\mathrm{HM}=$ hora máquina; $\mathrm{mm}=$ milímetros; $\mathrm{kg} \mathrm{ha}^{-1}=$ quilos por hectare; $\mathrm{sc} \mathrm{ha}^{-1}=$ sacos por hectare; 1 ha-1 $=$ litros por hectare. } \\
\hline
\end{tabular}


planícies dos Estados Unidos, avaliando-se a diversificação de sistemas de cultivo com forrageiras, houve aumento da produtividade das culturas de grãos, o que reduziu a pressão das plantas daninhas e melhorou a qualidade física do solo, visto que a forrageira tem efeito supressor na germinação e emergência de plantas daninhas. Além disso, esse sistema acelera a formação da pastagem.

De maneira geral, a silagem de sorgo apresentou custo de produção inferior ao da silagem de milho. Em alguns casos, a silagem de sorgo pode apresentar também maior produtividade de massa seca que a do milho, tendo em vista a maior rusticidade da cultura do sorgo, que a torna excelente opção como fonte de volumoso para animais, produzindo silagem de boa qualidade (Rocha Júnior et al., 2010; Nascimento et al., 2008; Benício et al., 2011). Essa resposta não foi observada neste trabalho, pelo fato de a silagem ter sido cultivada em consórcio com forrageiras tropicais, o que pode ter influenciado na produtividade de massa seca pelo possível efeito de competição entre as espécies. Entretanto, cabe destacar as elevadas produtividades de massa seca (PMS) das silagens de sorgo (Neumann et al., 2008; Magalhães et al., 2010) em todos os sistemas avaliados durante os dois anos agrícolas.
Os custos operacionais totais (COT), para cada sistema de produção, nos dois anos em avaliação, assim como para produtividade de massa seca (PMS), proteína bruta (PB) e nutrientes digestíveis totais (NDT), por área, estão na Tabela 2, apresentados em $\mathrm{kg} \mathrm{ha}^{-1}$.

Verifica-se que, entre os sistemas de produção, os maiores COT foram do milho em consórcio com a $B$. brizantha cv. Xaraés (MB), com valor de R\$2.046,93 e de $\mathrm{R} \$ 2.385,40$ por hectare e, os menores, para o sorgo cultivado exclusivamente, ou seja, solteiro (SS), com valor de $\mathrm{R} \$ 1.815,93$ e de $\mathrm{R} \$ 1.941,62$, para os dois anos em avaliação (safras 2010/2011 e 2011/2012), respectivamente (Tabela 2).

As culturas do milho e do sorgo são as mais adaptadas e utilizadas no processo de ensilagem em condições de Cerrado. Isso se deve à facilidade de cultivo, altos rendimentos e, principalmente, à qualidade da silagem produzida, sem necessidade de aditivos para estimular a fermentação. Em contrapartida, em vista da necessidade de suplementação alimentar na seca (inverno), período este em que há maior escassez de alimentos volumosos, o processo de ensilagem tem sido amplamente estudado com o intuito de suprir essas deficiências, melhorando o valor nutritivo da dieta,

Tabela 2. Custo operacional total (COT), produtividade de massa seca (PMS), proteína bruta (PB) e nutrientes digestíveis totais (NDT) por área $\left(\mathrm{kg} \mathrm{ha}^{-1}\right)$ de silagens no sistema plantio direto sob diferentes sistemas produtivos. Selvíria. Mato Grosso do Sul. Safras 2010/2011 e 2011/2012

\begin{tabular}{|c|c|c|c|c|}
\hline \multirow{3}{*}{ Tratamentos } & COT & $\mathbf{P M S}^{\text {ns }}$ & PB ** & NDT* \\
\hline & $\mathrm{R} \$$ & $\mathrm{~kg} \mathrm{ha}^{-1}$ & $\mathrm{~kg} \mathrm{ha}^{-1}$ & $\mathrm{~kg} \mathrm{ha}^{-1}$ \\
\hline & \multicolumn{4}{|c|}{ Safra 2010/2011 } \\
\hline $\mathrm{SS}^{\#}$ & $1.815,93$ & 27.930 & $1.078,78 \mathrm{c}$ & $19.464,35 \mathrm{ab}$ \\
\hline SP & $1.998,95$ & 21.780 & $1.295,83 \mathrm{c}$ & $14.926,78 \mathrm{~b}$ \\
\hline SB & $2.010,71$ & 25.195 & $1.175,85 \mathrm{c}$ & $17.613,83 \mathrm{ab}$ \\
\hline MS & $1.852,16$ & 28.550 & $1.639,95 \mathrm{~b}$ & $20.525,65 \mathrm{a}$ \\
\hline MP & $2.035,17$ & 26.425 & $1.919,50 \mathrm{a}$ & $18.816,48 \mathrm{ab}$ \\
\hline MB & $2.046,93$ & 27.113 & $1.627,00 \mathrm{~b}$ & $19.229,95 \mathrm{ab}$ \\
\hline \multirow[t]{2}{*}{$\mathrm{CV} \%$} & - & 12,13 & 7,56 & 12,54 \\
\hline & COT & PMS $^{*}$ & PB $* *$ & NDT** \\
\hline \multirow[t]{2}{*}{ Tratamentos } & $\mathrm{R} \$$ & $\mathrm{~kg} \mathrm{ha}^{-1}$ & $\mathrm{~kg} \mathrm{ha}^{-1}$ & $\mathrm{~kg} \mathrm{ha}^{-1}$ \\
\hline & \multicolumn{4}{|c|}{ Safra 2011/2012 } \\
\hline $\mathrm{SS}^{\#}$ & $1.941,62$ & $32.012 \mathrm{a}$ & $1.640,85 \mathrm{~b}$ & $20.999,17 \mathrm{~b}$ \\
\hline SP & $2.132,72$ & $35.087 \mathrm{a}$ & $1.498,06 \mathrm{bc}$ & $22.526,95 \mathrm{ab}$ \\
\hline SB & $2.169,47$ & $24.112 b$ & $1.120,06 \mathrm{c}$ & $16.101,84 \mathrm{c}$ \\
\hline MS & $2.158,55$ & $32.212 \mathrm{a}$ & $2.245,34 \mathrm{a}$ & $22.996,67 \mathrm{ab}$ \\
\hline MP & $2.349,65$ & $36.900 \mathrm{a}$ & $2.166,27 \mathrm{a}$ & $26.103,40 \mathrm{a}$ \\
\hline MB & $2.386,40$ & $30.588 \mathrm{ab}$ & $1.797,41 \mathrm{ab}$ & $22.020,31 \mathrm{ab}$ \\
\hline
\end{tabular}

Médias seguidas por letras distintas nas colunas diferem entre si pelo teste de Tukey a $5 \%$ de probabilidade, onde: ${ }^{* * *,}$, ns: $(\mathrm{P}<0,01),(\mathrm{P}<0,05)$ e $(\mathrm{P}>0,05)$, respectivamente.

\# SS: sorgo semeado exclusivamente (solteiro); SP: sorgo em consórcio com o Panicum maximum cv. Tanzânia; SB: sorgo em consórcio com a Brachiaria brizantha cv. Xaraés; MS: milho semeado exclusivamente (solteiro); MP: milho em consórcio com o Panicum maximum cv. Tanzânia e MB: milho em consórcio com a Brachiaria brizantha cv. Xaraés, respectivamente. 
podendo reduzir os gastos com a utilização de concentrados e melhorando a eficiência produtiva das propriedades rurais, garantindo maior lucro e sustentabilidade no setor agrícola.

Deste modo, verificaram-se elevadas produtividades de massa seca (PMS), em todos os sistemas de produção analisados, com destaque para o tratamento MS, no ano 2010/2011, e para o MP, no ano 2011/2012, enquanto, nos sistemas SP e SB resultaram menores as PMS, nos dois anos em avaliação, respectivamente (Tabela 2). Neste contexto, de acordo com Paziani et al. (2009), as características mais desejáveis em uma cultura para a ensilagem são a elevada produção de matéria verde e seca, tanto no ponto de ensilagem como na maturidade fisiológica, e as altas concentrações de proteína bruta e energia, fatores que garantem maior digestibilidade da forragem.

Assim, as altas produtividades obtidas nesta pesquisa (Tabela 2), tanto nos cultivos solteiros quanto nos cultivos consorciados, devem-se à alta tecnologia adotada nestes sistemas de produção, com adubação adequada à grande exigência das culturas, cultivo sob sistema plantio direto, e a irrigação fornecida.

Os resultados obtidos para PMS, neste trabalho, mesmo considerando-se somente a cultura do milho cultivado exclusivamente, ou seja, solteiro (MS), foram superiores aos encontrados por Paziani et al. (2009), que obtiveram, também avaliando silagem de milho, produtividades médias de massa verde de 50,47 $\mathrm{t} \mathrm{ha}^{-1} \mathrm{e}$, de matéria seca, de 18,69 $\mathrm{t} \mathrm{ha}^{-1}$. Estas produtividades podem ser consideradas acima da média, em comparação com as médias obtidas na prática, garantindo, assim, elevado potencial produtivo de matéria verde e de matéria seca ensilável, por unidade de área, principalmente, considerando-se o espaçamento utilizado nesta pesquisa $(0,90 \mathrm{~m})$ e o fato de o milho estar sendo cultivado em consórcio com espécies forrageiras, haja vista que pode haver competição entre as espécies.

De acordo com Crusciol et al. (2009), o consórcio do milho ou do sorgo com gramíneas forrageiras, como as do gênero Brachiaria ou Panicum, é possível, em função das diferenças entre as taxas de acúmulo de biomassa desses cereais e as das forrageiras, sendo que o crescimento inicial da forrageira é mais lento. Assim, as culturas do milho e do sorgo se estabelecem primeiro, não sendo necessário, na maioria dos casos, o uso de herbicidas para retardar o crescimento da forrageira, como foi constatado também neste trabalho.

Verificaram-se elevadas produções de proteína bruta $(\mathrm{PB})$ e de nutrientes digestíveis totais (NDT), por área (Tabela 2), sendo estes nutrientes de extrema im- portância para adequada nutrição animal. Os valores de proteína bruta variaram de 4,33 a 7,09\% na matéria seca, no primeiro ano agrícola, e de 3,74 a 7,34\%, no segundo ano, respectivamente, sendo estes valores próximos aos verificados por Paziani et al. (2009), em silagens de capim-tanzânia, e aos 7\% recomendados por Van Soest (1994), valor este considerado como mínimo aceitável para manutenção da população de micro-organismos do rúmen de bovinos. No entanto, nutricionalmente, é recomendada a suplementação com fontes proteicas a animais recebendo silagens de gramíneas, conforme sugeriram Pimentel et al. (1998).

Com relação à produção de $\mathrm{PB}$ por área $\left(\mathrm{kg} \mathrm{ha}^{-1}\right)$, foram constatados elevados valores, variando de $1.078,78 \mathrm{~kg} \mathrm{ha}^{-1}$, no tratamento SS, a $1.639,95 \mathrm{~kg} \mathrm{ha}^{-1}$, no tratamento MS, no primeiro ano agrícola (2010/ 2011), e de 1.120,06 $\mathrm{kg} \mathrm{ha}^{-1}$, no tratamento SB, a 2.245,34 $\mathrm{kg} \mathrm{ha}^{-1}$, no tratamento MS, no segundo ano de avaliação (Tabela 2). Esses resultados demonstram a eficiência desses sistemas produtivos, e podem resultar em elevadas quantidades de energia ha $^{-1}$, garantindo, desta maneira, adequado valor energético em silagens, na região em estudo.

Os valores de NDT variaram entre 54,28 e 59,22\% no primeiro ano e de 63,80 a $74,51 \%$, no segundo ano agrícola, respectivamente. No geral, ficaram acima dos $55 \%$, relatados como ideais por Van Soest (1994), em forrageiras tropicais. Verifica-se, portanto, sua alta produtividade, com valores entre $14.926,78 \mathrm{~kg} \mathrm{ha}^{-1}$, no tratamento SP, e 20.525,65 $\mathrm{kg} \mathrm{ha}^{-1}$, no tratamento MS, para o primeiro ano agrícola, e valores entre 16.101,84, no tratamento SB, e 26.103,40, no tratamento MP, para o segundo ano agrícola, respectivamente, proporcionando, desta maneira, material com boa qualidade nutricional (Tabela 2).

Desta forma, salientam-se novamente as vantagens destes sistemas de produção na ILP sob SPD, pois, além da alta produção de massa seca ha-1, verificou-se também um material de boa qualidade bromatológica e nutricional, podendo servir como alimento de excelente qualidade para bovinos, o que pode gerar maior diversificação dos sistemas produtivos, garantindo também maior renda ao produtor rural.

No entanto, a comparação destes dados com os de outros autores não é possível, tendo em vista a escassez de trabalhos que quantificam a produção energética, por área, de forrageiras tropicais, principalmente quando consorciadas. Os dados deste trabalho foram superiores aos obtidos por Leonel et al. (2008), avaliando o consórcio do capim-braquiária e milho, quanto à produtividade das culturas e às características qualitativas das silagens feitas com plantas em diferentes idades. Esses 
autores afirmam, ainda, que, em todas as avaliações, os maiores valores de PB e NDT foram obtidos quando o milho foi cultivado em consórcio com a braquiária. Entre esses estudos, destacam-se ainda os obtidos por Zago (2002), avaliando estes mesmos parâmetros em silagens de sorgo, que relatou produção de NDT de 4.400 a 10.800 $\mathrm{kg} \mathrm{ha}^{-1}$.

Os valores obtidos nesta pesquisa, para PB e NDT, por área, foram maiores que os relatados por Leonel et al. (2009), avaliando a Brachiaria brizantha cv. MG-5, implantada por ocasião do consórcio com a cultura do milho, em diferentes modalidades de cultivo. Esses autores enfatizam ainda a importância de se buscar o máximo potencial produtivo em matéria seca (MS) da pastagem e de fazer uso da suplementação do pasto em nutrientes, com vistas ao aumento do desempenho animal individual e da produção animal por área. Desta forma, as silagens produzidas nesta pesquisa, além de proporcionarem maior quantidade de massa seca, foram mais energéticas quando comparadas apenas com a forragem de capim braquiária.

Assim, apesar de as culturas do milho e do sorgo serem as mais utilizadas para a produção de silagem, seus custos de produção têm sido o fator limitante da utilização pelos pecuaristas, tornando-se de extrema importância o estudo sistematizado do seu custo de produção e das vantagens que este sistema pode proporcionar ao produtor rural. Da mesma forma, as forrageiras comumente utilizadas estão sujeitas à estacionalidade de produção, resultando em grande deficiência quantitativa e qualitativa de forragem, no período de estiagem no Cerrado, de maneira que a silagem produzida no verão pode servir como alimento de elevada qualidade nutricional no período de inverno.

Nesta pesquisa, verifica-se o reduzido custo de produção das silagens neste sistema produtivo (Tabela 2). Os valores de produção variaram entre $\mathrm{R} \$ 0,06$ e R $\$ 0,09$ para cada $\mathrm{kg}$ de matéria seca, nos dois anos em avaliação. Entretanto, esses custos foram inferiores ao de $\mathrm{R} \$$ 0,20 por $\mathrm{kg}$ de massa seca de silagem de milho, relatado no Anualpec (2012). Sendo assim, pode-se considerar que houve uma diluição dos custos pela alta produtividade de massa seca.

Os custos na obtenção dos teores de PB e NDT por área também foram bastante atrativos, com valores mínimos, de $\mathrm{R} \$ 1,06$ a $\mathrm{R} \$ 1,68$ para cada $\mathrm{kg}$ PB produzido por hectare, para os tratamentos MP e SS, no primeiro ano agrícola, e de $\mathrm{R} \$ 0,96$ a $\mathrm{R} \$ 1,94$ para cada $\mathrm{kg}$ de $\mathrm{PB}$, para os tratamentos MS e SB, no segundo ano de avaliação, respectivamente. Os valores médios da produção de NDT, nos dois anos avaliados, variaram entre R \$ 0,09 e R $\$ 0,13$ para cada $\mathrm{kg}$ de NDT produzido por hectare (Tabela 2).
Os custos de produção obtidos neste trabalho demonstraram as vantagens da utilização destas espécies na produção de silagem de boa qualidade e os reduzidos custos na produção de alimentos altamente energéticos na região em estudo, levando-se em consideração as mesmas condições adotadas nesta pesquisa. Portanto, a otimização de sistemas intensivos de produção pecuária, como os demonstrados por esta pesquisa, depende ainda da produção de silagem de baixo custo e de alto valor nutritivo, para que o giro de capital investido seja feito no menor tempo possível (Brondani et al., 2000).

De maneira geral, apesar de as culturas solteiras (SS e MS) terem apresentado maiores valores absolutos dos parâmetros avaliados (PMS, PB e NDT), com exceção do COT, os sistemas em consórcio apresentam a conveniência de deixar a pastagem pré-estabelecida, propiciando redução dos custos durante o ano, pela produção de forragem na entressafra, período caracterizado pela escassez de alimentos, de maneira que esta pastagem poderá servir como alimento de boa qualidade nutricional a pasto,ou, fornecida diretamente no cocho. As forrageiras produzidas nestes sistemas produtivos podem servir, ainda, para a manutenção e continuidade do sistema plantio direto, gerando maior sustentabilidade aos sistemas de produção, tendo em vista os benefícios da palhada para o solo e para as culturas em sucessão.

\section{CONCLUSÃO}

Os maiores COTs foram obtidos no consórcio de milho com capim Xaraés ( $\mathrm{R} \$ 2.046,93$ e R\$2.385,40 por hectare) e, os menores, nos cultivos de sorgo solteiro ( $\mathrm{R} \$ 1.815,93$ e $\mathrm{R} \$ 1.941,62)$, para os dois anos agrícolas.

Os tratamentos com cultivo exclusivo, tanto de sorgo quanto de milho, proporcionaram maiores valores de PMS, no primeiro ano. Entretanto, no segundo ano, os maiores valores de PMS foram proporcionados pelos cultivos consorciados de ambas as espécies com Panicum maximum cv. Tanzânia.

Os valores de PB e NDT por área variaram entre os tratamentos, nos dois anos agrícolas. Contudo, no geral seguiram o padrão da PMS, cujos maiores valores foram proporcionados pelos consórcios de sorgo e milho com Panicum maximum cv. Tanzânia.

\section{AGRADECIMENTOS}

À FAPESP pela concessão de bolsa de doutorado à primeira autora e pelo apoio financeiro ao projeto (Processo $n^{\circ}$ 2011/01057-0). 


\section{REFERÊNCIAS}

Agrianual (2011) Anuário da Agricultura Brasileira. São Paulo, AgraFNP. p.104-113.

Agrianual (2012) Anuário da Agricultura Brasileira. São Paulo, AgraFNP. $482 \mathrm{p}$.

Anualpec (2010) Anuário da Pecuária Brasileira. São Paulo, AgraFNP. p.182-192.

Anualpec (2012) Anuário da pecuária brasileira. São Paulo, Instituto FNP. 378p.

Benício LPF, Oliveira VA, Silva LL, Rosanova C \& Lima SO (2011) Produção de Megathyrsus maximum consorciado com sorgo sob diferentes fontes de fósforo. Tecnologia \& Ciência Agropecuária, 5:5560 .

Brondani IL, Alves Filho DC \& Bernardes RAC (2000) Silagem de alta qualidade para bovinos. In: Restle J (Ed.) Eficiência na produção de bovinos de corte. Santa Maria, Universidade Federal de Santa Maria. p.147-184.

Costa NR, Andreotti M, Gameiro RA, Pariz CM, Buzetti S \& Lopes KSM (2012) Adubação nitrogenada no consórcio de milho com duas espécies de braquiária em sistema plantio direto. Pesquisa Agropecuária Brasileira, 47:1038-1047.

Crusciol CAC, Mateus GP, Nascente AS, Martins PO, Borghi E \& Pariz CM (2012) An innovative crop-forage intercrop system: early cycle soybean cultivars and palisadegrass. Agronomy Journal, 104:10851095

Crusciol CAC, Soratto RP, Borghi E \& Mateus GP (2009) Integração Lavoura-pecuária: Benefícios das gramíneas perenes nos sistemas de produção. Campinas, Informações Agronômicas. 15p.

Doorenbos J \& Pruitt WO (1977) Guidelines for predicting crop water requirements. Rome, FAO. 179p. (Irrigation and Drainage Paper, 24)

EMBRAPA - Empresa Brasileira de Pesquisa Agropecuária (2006) Sistema brasileiro de classificação dos solos. $2^{\mathrm{a}}$ ed. Rio de Janeiro, CNPS $212 p$.

Entz MH, Baron VS, Carr PM, Meyer DW, Smith Júnior SR \& Mccaughey WP (2002) Potential of forages to diversify cropping systems in the Northern Great Plains. Agronomy Journal, 94:240-250.

Ferreira DF (1999) Sisvar: sistema de análise de variância. Lavras, Universidade Federal de Lavras. 30p.

Ferreira JJ (2001) Estágio de maturação do milho e do sorgo o ideal para ensilagem. In: CRUZ, J. C. et al. (Ed.). Produção e utilização de silagem de milho e sorgo. Sete Lagoas, Embrapa Milho e Sorgo, p.405-428.

Garcia CMP, Andreotti M, Tarsitano MAA, Teixeira Filho MCM, Lima AES \& Buzetti S (2012) Análise econômica da produtividade de grãos de milho consorciado com forrageiras dos gêneros Brachiaria e Panicum em sistema plantio direto. Revista Ceres, 59:157-163.

Kluthcouski J, Cobucci T, Aidar H, Yokoyama LP, Oliveira IP, Costa JLS Vilela L, Barcellos AO \& Magnabosco CU (2000) Sistema Santa Fé tecnologia Embrapa: integração lavoura-Pecuária pelo consórcio de culturas anuais com forrageiras, em áreas de lavoura, nos sistemas direto e convencional. Santo Antônio de Goiás, Embrapa Arroz e Feijão. 28p. (Circular Técnica, 38).

Landers JN (2007) Tropical crop-livestock systems in conservation agriculture: the Brazilian experience. In: Landers JN (Ed.). Integrated Crop Management. Rome, Food and Agriculture Organization of the United Nations. 92p.

Leonel FP, Pereira JC, Costa MG, Marco Júnior P, Lara LA \& Queiroz AC (2009) Comportamento produtivo e características nutricionais do capim-braquiária cultivado em consórcio com milho. Revista Brasileira de Zootecnia, 38:177-189.
Leonel FP, Pereira JC, Costa MG, Marco Júnior P, Lara LA, Ribeiro MD \& Silva CJ (2008) Consórcio capim-braquiária e milho: produtividade das culturas e características qualitativas das silagens feitas com plantas em diferentes idades. Revista Brasileira de Zootecnia, 37:22332242

Macedo MCMM (2009) Integração lavoura e pecuária: o estado da arte e inovações tecnológicas. Revista Brasileira de Zootecnia, 38:133146

Magalhães RT, Gonçalves LC, Borges I, Rodrigues JAS \& Fonseca JF (2010) Produção e composição bromatológica de vinte e cinco genótipos de sorgo (Sorghum bicolor (L.) Moench). Arquivo Brasileiro de Medicina Veterinária e Zootecnia, 62:747-751.

Matsunaga M, Bemelmans PF \& Toledo PEN (1976) Metodologia de custo de produção utilizada pelo IEA. Agricultura em São Paulo, 23:123-139.

Molina LR, Rodriguez NM, Souza BM Gonçalves L.C. \& Borges I (2003) Parâmetros da degradabilidade potencial da matéria seca e da proteína bruta das silagens de sorgo (Sorghum bicolor (L.) Moench), com e sem tanino no grão, avaliados pela técnica in situ. Revista Brasileira de Zootecnia, 32:222-228.

Montes SMNM, Firetti R, Golla AR \& Tarsitano MAA (2006) Custos e rentabilidade da batata-doce (Ipomoea batatas L.) na região oeste do Estado de São Paulo: estudo de caso. Informações Econômicas, $36: 15-23$.

Nascimento WG, Prado IN, Jobim CC, Emile JC, Surault F \& Huyghe C (2008) Valor alimentício das silagens de milho e de sorgo e sua influência no desempenho de vacas leiteiras. Revista Brasileira de Zootecnia, 37: 896-904.

Neumann M, Ost PR, Pellegrini LG \& Defaveri FJ (2008) Comportamento de híbridos de milho (Zea mays) e sorgo (Sorghum bicolor) para silagem na região centro-sul do Paraná. Ambiência Guarapuava, 4:237250

Nicoloso RS, Lanzanova ME \& Lovato T (2006) Manejo das pastagens de inverno e potencial produtivo de sistemas de integração lavourapecuária no Estado do Rio Grande do Sul. Ciência Rural, 36:17991805 .

National Research Council (NRC) (2001) Nutrient requeriments of dairy cattle. $7^{\mathrm{a}}$ ed. Washington, National Academy Press. 381p.

Nussio LG, Campos FP \& Dias FN (2001) Importância da qualidade da porção vegetativa no valor alimentício da silagem de milho. In: Simpósio sobre produção e utilização de forragens conservadas, Maringá. Anais, UEM. p.127-145.

Pariz CM, Andreotti M, Tarsitano MAA, Bergamaschine AF, Buzetti S \& Chioderolli CA (2009) Desempenhos técnicos e econômicos da consorciação de milho com forrageiras dos gêneros Panicum e Brachiaria em sistema de integração lavoura-pecuária. Pesquisa Agropecuária Tropical, 39:360-370.

Pariz CM, Andreotti M, Azenha MV, Bergamaschine AF, Mello LMM \& Lima RC (2011) Produtividade de grãos de milho e massa seca de braquiárias em consórcio no sistema de integração lavoura-pecuária. Ciência Rural, 41:875-882.

Paziani SF, Duarte AP, Nussio LG, Gallo PB, Bittar CMM, Zopollatto M \& Reco PC (2009) Características agronômicas e bromatológicas de híbridos de milho para produção de silagem. Revista Brasileira de Zootecnia, 38:411-417.

Pereira MN, Von Pinho RG, Bruno RGS \& Calestine GA (2004) Ruminal degradability of hard or soft texture corn grain at three maturity stages. Scientia Agricola, 61:358-363.

Pimentel JJO, Silva JFC, Valadares Filho SC Cecon PR \& Santos OS (1998) Efeito da suplementação proteica no valor nutritivo de silagens de milho e sorgo. Revista Brasileira de Zootecnia, 27:1042-1049.

Rev. Ceres, Viçosa, v. 62, n.1, p. 009-019, jan/fev, 2015 
Rocha Júnior VR, Gonçalves LC, Rodrigues JAS, Brito AF, Rodriguez NM \& Borges I (2010) Avaliação de sete genótipos de sorgo (Sorghum bicolor (L.) Moench) para produção de silagem: I. características agronômicas. Arquivo Brasileiro de Medicina Veterinária e Zootecnia, 52:506-511.

Silva DJ \& Queiroz AC (2002) Análise de Alimentos: Métodos Químicos e Biológicos. $3^{\mathrm{a}}$ ed. Viçosa, UFV. 235p.

Tracy BF \& Zhang Y (2008) Soil compaction, corn yield response, and soil nutrient pool dynamics within an integrated crop-livestock system in Illinois. Crop Science, 48:1211-1218.
Trecenti R, Oliveira MC \& Hass G (2008) Integração lavoura-pecuáriasilvicultura. Brasília, MAPA/SDC. 54p. (Boletim técnico).

Van Soest PJ (1994) Nutritional ecology of the ruminant. $2^{\mathrm{a}}$ ed. New York, Cornell University. 476p.

Zago CP (2002) Híbridos de milho e sorgo para silagem: características agronômicas e nutricionais. In: I ${ }^{\circ}$ Simpósio sobre manejo estratégico da pastagem, Viçosa. Anais, Universidade Federal de Viçosa. p.351371. 